\title{
Common mental disorders and risk factors in rural India: baseline data from the SMART mental health project
}

\author{
Sudha Kallakuri, Siddhardha Devarapalli, Anadya Prakash Tripathi, Anushka Patel and Pallab K Maulik
}

\section{Background}

About 10\% Indians suffer from stress, depression or substance use disorders. Few receive care for these problems, especially in rural areas.

\section{Aims}

As part of a broader initiative to deliver technology-enabled mental health services for rural communities (adults $\geq 18$ years), information was collected about the prevalence of depression, anxiety and suicide risk.

\section{Method}

The study was conducted in 12 villages in the West Godavari district of Andhra Pradesh. Depression and anxiety were assessed using the Patient Health Questionnaire-9 and Generalized Anxiety Disorder-7, respectively. Additionally, data were collected about sociodemographic factors and stressful events, among others.

\section{Results}

Anxiety, depression and suicidal ideation affected 10.8, 14.4 and $3.5 \%$ of participants, respectively $(N=22377)$. These were more common among women, and among those who were aged 30-59 years, uneducated, or divorced/ separated/ widowed. Stress due to financial loss was significant.

\section{Conclusions}

The study identified a significant number of people at risk of depression, anxiety and suicide, and needing care.

\section{Declaration of interest}

None.

\section{Keywords}

Mental health services; rural communities; common mental disorders; low- and middle-income countries; India; epidemiology; mental health intervention.

\section{Copyright and usage}

(C) The Royal College of Psychiatrists 2018. This is an Open Access article, distributed under the terms of the Creative Commons Attribution-NonCommercial-NoDerivatives licence (http://creativecommons.org/licenses/by-nc-nd/4.0/), which permits noncommercial re-use, distribution, and reproduction in any medium, provided the original work is unaltered and is properly cited. The written permission of Cambridge University Press must be obtained for commercial re-use or in order to create a derivative work.
Around $70-80 \%$ of the population in India currently live in rural settings without access to good quality healthcare facilities. ${ }^{1}$ The establishment of primary health centres (PHCs) has helped improve affordability and accessibility of healthcare to some extent, for some conditions, but it has been largely ineffective in addressing the needs of people suffering from or at risk of non-communicable disorders including mental disorders. ${ }^{2-4}$ It has been estimated that only 1 in 27 receive care for mental disorders such as depression. ${ }^{5}$ The National Mental Health Survey (NMHS) ${ }^{6}$ estimated that about 150 million Indians need care for mental disorders, and about $10 \%$ suffer from common mental disorders (CMD) such as depression, anxiety, emotional stress and suicide risk, as well as alcohol and drug use. The report indicated that the prevalence of mental disorders was 2-3 times higher in urban areas, compared with rural areas. ${ }^{7}$ However, relatively few studies have used standardised tools to assess the burden of CMD, especially in rural settings. Thus, there is a need to provide further evidence about the burden of mental disorders, especially in rural communities and particularly using standardised tools and methods. In the absence of reliable disease prevalence estimates, planning an appropriate health system response is challenging. This paper reports on the baseline data from the Systematic Medical Appraisal, Referral and Treatment (SMART) Mental Health Project. ${ }^{8}$ It outlines the prevalence of CMD such as depression, anxiety and suicidal ideation, and risk factors associated with those conditions. However, the SMART Mental Health Project had the broader objective of conducting a study to assess feasibility and acceptability, and gather preliminary evidence about a mobile technology-based mental health services delivery model for rural India.

\section{Method}

\section{Study setting and sample size estimation}

The study was conducted in 12 villages (total population of $\sim 40000$ ) of the West Godavari district in the state of Andhra Pradesh in south India. West Godavari is a coastal district in Andhra Pradesh, with a population of $\sim 4$ million. Telugu is the predominant language of the region, and agriculture and fisheries are the main sources of occupations and income (http://www.ap.gov. in/about-ap/districts/west-godavari/). Initially, three primary health centres (PHCs) within 50 kilometres from the field office were selected. All villages catered by those PHCs were listed. Prior to randomisation, it was ensured that the villages had adequate numbers of lay village health workers - Accredited Social Health Activists (ASHAs) - to cater to the population. This was necessary as the subsequent stages of the project included delivering a complex intervention on mental health service delivery involving the ASHAs. ${ }^{8,9}$ Four villages per PHC were then selected randomly.

\section{Sample size estimation}

Since the SMART Mental Health Project was essentially a mental health services delivery project, the sample size estimates were 
done keeping in perspective the primary outcome of use of mental health services and the availability of ASHAs. We anticipated that 12 villages would have a population of $\sim 27000$ individuals aged $\geq 18$ years. Based on our extensive previous work, we expected a response rate of $\sim 75 \%$, indicating $\sim 19500$ participants. It was conservatively estimated that $15 \%$ of consenting participants at baseline would have a CMD as determined by the screening tools, representing approximately 3000-4000 individuals. Studies have estimated that only $15-25 \%$ of those with severe mental disorders in developing countries receive treatment, with even lower numbers for CMD. ${ }^{10}$ Thus, we conservatively assumed that $10 \%$ of individuals who screened positive would have sought medical care for mental disorders in the previous 12 months at baseline. For every 1000 population there is one ASHA, and they were identified as the clusters for analyses. An earlier study that focused on provision of mental health services in India using primary care workers had found an intraclass correlation (ICC) of $0.03 .^{11}$ Given that this study had a behavioural intervention, we assumed an ICC of 0.1 . With these assumptions, the study had $80 \%$ power at $\alpha=0.05$ to detect a relative increase in mental healthcare utilisation by as little as $20 \%$ at followup, if we had 38 clusters with 80 individuals in each cluster.

\section{Ethics approval and consent of participants}

Ethics approval was obtained from the Centre for Chronic Disease Control in New Delhi, India. Written informed consent was obtained from all the participants. All consenting adults $\geq 18$ years old who understood the questions and instructions, and were not limited by any severe illness that prevented them from giving the interview, were included.

Prior to the start of the study, permission was obtained from the Directorate of Health, Government of Andhra Pradesh, and the support of the District Medical Health Officer of the West Godavari region was sought. In addition, approval was obtained from all local village administrative bodies.

\section{Baseline data collection}

Initially, a formative phase was initiated, in which the data collection tools were tested and finalised. ${ }^{12}$ This was followed by an anti-stigma campaign, which was rolled out for 3 months across all the villages to increase knowledge, improve attitudes and behaviours related to mental health, and reduce negative perceptions related to helpseeking. Subsequently, baseline data were collected over a 3-month period, using a household survey conducted by trained interviewers.

\section{Tools used and generation of electronic database}

Depression and anxiety were assessed using the Patient Health Questionnaire-9 Item (PHQ9) ${ }^{13,14}$ and the Generalized Anxiety Disorder-7 Item (GAD7), ${ }^{14,15}$ respectively. The PHQ9 consists of nine items. Scores of $0,1,2$, or 3 are assigned to the response categories of 'not at all', 'several days', 'more than half the days' and 'nearly every day', respectively. The total score for the nine items ranges from 0 to 27 , with scores of 5-9 indicating mild, 10-14 indicating moderate, and 15-27 indicating severe depression. A cut-off score of $\geq 10$ has been recommended as indicating the possibility of clinically relevant moderate depression requiring further assessment. ${ }^{13-15}$ The last item on the PHQ9 specifically relates to ideas of self-harm and is indicative of increased suicide risk. The GAD7 consists of seven items. Scores of $0,1,2$, and 3 are assigned to the response categories of 'not at all', 'several days', 'more than half the days' and 'nearly every day', respectively. The total score ranges from $0-21$, with a score of 5-9 indicating mild, 10-14 indicating moderate, and 15-21 indicating severe generalised anxiety. A cut-off score of $\geq 10$ has been used as indicative of clinically relevant moderate anxiety requiring further assessment and follow-up. ${ }^{13-15}$ The PHQ9 in the local language, Telugu, has been validated in India, ${ }^{16}$ while GAD7 has been translated and backtranslated into Telugu. For this study, a score of $\geq 10$ on either the PHQ9 or GAD7 and /or a score of $\geq 1$ on the PHQ9 question on self-harm was considered indicative of screening positive for CMD, while a score of 5-9 was considered indicative of mild depression. Both PHQ9 and GAD7 have been used widely in research and have been shown to capture depression and anxiety across different settings. ${ }^{17-19}$ Data were also collected about the following.

- Sociodemographic factors - gender, education, marital status, occupation, age.

- Stressful life events - these were captured using a set of questions which inquired about major life events in the past 1 year, adapted from the Epidemiologic Catchment Area study. ${ }^{20}$

- Mental health knowledge, attitudes and behaviours - Likert-type responses to 16 questions were used to assess knowledge, attitudes and behaviours related to mental health. ${ }^{21}$ This tool was translated and back translated to Telugu.

- Stigma perceptions related to help-seeking for mental disorders this was assessed using the Barriers to Care Evaluation Treatment Stigma subscale, ${ }^{22}$ which includes 12 questions and uses Likert-type responses. This tool was translated and back translated to Telugu.

- Alcohol and substance use - this information was gathered using the ASSIST questionnaire. ${ }^{23}$ This tool was translated and back translated to Telugu.

- Social networks and social support - questions were asked about the number of family members, relatives or friends that the person was in contact with in the past 1 year, and about how helpful such people were when discussing personal problems or lending money when needed.

- Past history of physical and mental disorders, family history of prior mental disorders and past history of treatment for mental disorders - specific questions were asked to gather information on each of these.

\section{Data management and data analysis}

All data were captured electronically on seven-inch Android tablets and uploaded on-the-go using cloud computing whenever network access was available. The data were stored on secure servers. All data stored on the servers were initially cleaned and errors were rectified. The clean data were downloaded and de-identified before being made accessible to the research team. Descriptive analyses are reported as proportions and means. For those reporting depression/anxiety scores $\geq 10$ or at increased risk of suicide (score $\geq 1$ on the question related to suicidal ideation in the PHQ9), differences in proportions between different sociodemographic factors such as gender, age and occupation and education were analysed. Univariate analysis was carried out for each factor and odds ratio (OR), and the $95 \% \mathrm{CI}$, and $\chi^{2} P$-values for differences in proportion were calculated for each factor. Since all our predictors were categorical in nature, the pairwise association between sets of predictors were checked by Cramér's V statistic for association prior to modelling, to identify collinearity which may have affected the relationship between the predictors. Logistic regression was then used to adjust for all the sociodemographic factors which were significant during univariate analysis. Adjusted ORs with 95\% Wald confidence intervals, along with $P$-values, were determined.

\section{Ethical standards}

The authors assert that all procedures contributing to this work comply with the ethical standards of the relevant national and 
institutional committees on human experimentation and with the Helsinki Declaration of 1975, as revised in 2008.

\section{Results}

Data were collected from 22377 individuals (50.1\% males and 49.9\% females) representing $80.3 \%$ of the total eligible population contacted in the 12 villages. Of the eligible individuals, 4848 (17.4\%) were not available for the interview as they had moved out of the villages in search of seasonal work; about $71 \%$ of these were males. Only $70(0.001 \%)$ individuals refused to be interviewed (Fig. 1).

Sociodemographic details are provided in Table 1. The samples were characterised by a higher proportion of females overall. Furthermore, a higher proportion of females compared to males either had no education or had studied until primary level, and a higher proportion of males had completed high school or college. The majority of participants worked in the unorganised sector, and more males were employed in both the organised and unorganised sectors. About $80 \%$ were married (with similar proportions for both genders), and the mean age of the population was 42.3 years.

Tables 2 and 3 outline the depression and anxiety characteristics of the population. Overall, $5.3 \%$ of the population were identified as screen positive (i.e. had either scored $\geq 10$ for depression or anxiety or scored $\geq 1$ on the question on suicidal ideas). Risk of depression and anxiety and suicidal ideas were more common in females, and this was statistically significant for each condition $(P<0.001)$. Overall, $3.5 \%$ responded positively to the question on suicidal ideas on PHQ-9, which indicated an increased risk of suicide. Based on the severity score, $10.8 \%$ were at risk of anxiety, of

Population contacted at baseline ( $N=27854$; Male (50.1\%), Female $49.9 \%)$

Population who had moved out of the

villages for temporary seasonal

work $(N=4848$; Male $(70.8 \%)$, Female $(29.2 \%)$

Population who had severe illness that prevented them from being interviewed $(N=474$; Male $(48.9 \%)$, Female $(51.1 \%))$

Population misclassified (age $<18$ years or duplicate entries) $(N=85$; Male (50.1\%), Female $(49.9 \%))$

Population who refused to be interviewed $(N=70$; Male (57.1\%), Female (42.8\%))
2237 22377)

\begin{tabular}{|c|c|c|c|}
\hline Characteristic & $\begin{array}{l}\text { Total } \\
\text { population (\%) }\end{array}$ & $\begin{array}{l}\text { Total males } \\
(\%)\end{array}$ & $\begin{array}{l}\text { Total females } \\
(\%)\end{array}$ \\
\hline \multicolumn{4}{|l|}{ Gender } \\
\hline Female & $12183(54.4)$ & & \\
\hline Male & $10194(45.6)$ & & \\
\hline \multicolumn{4}{|l|}{ Occupation } \\
\hline $\begin{array}{l}\text { Housewife/retired/ } \\
\text { other }^{\text {a }}\end{array}$ & $9416(42.1)$ & $1352(13.3)$ & $8064(66.1)$ \\
\hline Organised sector $^{\mathrm{b}}$ & 743 (3.3) & $591(5.8)$ & $152(1.2)$ \\
\hline $\begin{array}{l}\text { Unorganised } \\
\text { sector }^{\mathrm{C}}\end{array}$ & $12218(54.6)$ & $8251(80.9)$ & 3967 (32.6) \\
\hline \multicolumn{4}{|l|}{ Education } \\
\hline $\begin{array}{l}\text { Graduate/ } \\
\text { postgraduate }\end{array}$ & $1077(4.8)$ & $697(6.8)$ & $380(3.1)$ \\
\hline High school & $4407(19.7)$ & $2212(21.7)$ & $2195(18.0)$ \\
\hline Primary school & $9393(42.0)$ & 3967 (38.9) & $5426(44.5)$ \\
\hline No school & $7318(32.7)$ & 3150 (30.9) & $4170(34.2)$ \\
\hline Other ${ }^{d}$ & $180(0.8)$ & $168(1.6)$ & $12(0.1)$ \\
\hline \multicolumn{4}{|l|}{ Marital status } \\
\hline Currently married & 17895 (80.0) & $8282(81.2)$ & $9613(78.9)$ \\
\hline Never married & $2136(9.5)$ & $1565(15.4)$ & $571(4.7)$ \\
\hline $\begin{array}{l}\text { Separated/ } \\
\text { divorced/widowed }\end{array}$ & $2346(10.5)$ & $347(3.4)$ & 1999 (16.4) \\
\hline \multicolumn{4}{|l|}{ Age, years } \\
\hline Mean (SD) & $42.3(16.1)$ & $42.8(16.5)$ & $41.9(15.6)$ \\
\hline Range & $18-98$ & $18-96$ & $18-98$ \\
\hline \multicolumn{4}{|c|}{$\begin{array}{l}\text { Percentages may not add up to } 100 \% \text { owing to rounding off. } \\
\text { a Under occupation, the 'other' category includes students, those searching for jobs and } \\
\text { those unable to work because of any illness or old age. } \\
\text { b Includes jobs which involve paying a regular salary. } \\
\text { c Jobs which do not involve a regular salary such as farming, working as contractual } \\
\text { labourers, fishery. } \\
\text { d Under education, the 'other' category includes vocational training. }\end{array}$} \\
\hline
\end{tabular}

whom $1.4 \%$ had moderate or severe anxiety, and $14.4 \%$ were at risk of depression, of whom $2.5 \%$ had moderate/severe depression. Anxiety and depression were more severe among females.

Table 4 shows that gender, age, education, marital status and occupation were all significantly associated with the chances of screening positive. Being female, being older than 18-29 years, being unemployed (housewife/retired/other category), having no education (versus some education), and being married currently or being divorced/separated/widowed (compared to never married) were all sociodemographic characteristics associated with an increased odds of screening positive in the univariate analysis.

Using Cramér's V statistic to look for correlations, we found only occupation and gender to be correlated at a level of 0.5 (moderate correlation). Other predicators were poorly correlated. However, since both those variables were significant, we decided to keep them in the model. A logistic model adjusting for all the selected variables showed that the odds of screening positive were higher in females compared with males (OR 1.40, 95\% CI 1.20$1.64, P<0.001)$. Compared with the $18-29$-year-old age group, those aged $30-59$ years had significantly increased odds of screening positive, and those over 60 years had the highest risk (OR 2.81, 95\% CI 2.23-3.53, $P<0.001)$. Compared with those with some education, those with no education had increased chances of screening positive (OR 1.36, 95\% CI 1.19-1.55, $P<0.001$ ), and those separated/divorced/widowed had increased risk (OR 1.68, 95\% CI 1.16, 2.44, $P=0.01$ ).

Table 5 provides details of the different stressful events experienced by those who had moderate or severe depression/anxiety (score $\geq 10$ on PHQ9 or GAD7) compared with those who had no depression/anxiety or had only mild depression/anxiety (score $\leq 10$ on PHQ9/GAD7). 'Suffering a financial loss' in the past year was the most common stressful event, experienced by $56 \%$ individuals with moderate/severe depression or anxiety. All stressful 
Table 2 Number of screen-positive cases at baseline $(N=22377)$

\begin{tabular}{lcccc} 
Number of cases & Total population (\%) & Total males (\%) & Total females (\%) & $P$-value \\
Depression score $\geq 10$ & $546(2.4)$ & $189(1.9)$ & $357(2.9)$ & $<0.0001$ \\
Anxiety score $\geq 10$ & $313(1.4)$ & $105(1.0)$ & $208(1.7)$ & $<0.0001$ \\
Score $\geq 1$ on suicide-specific question & $785(3.5)$ & $253(2.5)$ & $532(4.4)$ & $<0.0001$ \\
${ }^{a}$ This tests for any statistical difference between genders. & & & & \\
\hline
\end{tabular}

events, except 'getting married', 'having a baby', 'losing a job' and 'retiring from job', were significantly more common in those who had moderate or severe depression or anxiety.

\section{Discussion}

We found that about $5.3 \%$ of participants were at risk of CMD. To our knowledge, this is the first study providing information on CMD from this community, and is the largest study providing such data from rural India. The strengths of the study were that standardised validated tools were used to assess CMD. Interviewers were trained and monitored during data collection. Random checks were made on the quality of the data, and any mismatch was clarified and corrected. Given that data were collected electronically, the chances of transcription error were reduced. In line with recent calls for gender-disaggregated analyses, ${ }^{24,25}$ we have tried to provide that in this paper, and found that women were significantly at increased risk of depression, anxiety and suicide.

The limitations of the study are that it is specific to one geographic area. The results can be generalised to other rural populations in the region, but its generalisability beyond similar rural populations may be difficult. The results do not include data on children and adolescents. Another limitation is that, as this was a crosssectional study, no causal inference can be drawn from the results, and only associations can be established. Suicidal ideation was captured using the single PHQ9 question, which only provides insight into one's thoughts; this is a risk indicator, but not a definitive clinical assessment of suicide risk, which would need further clinical assessment. Although alcohol use disorder can be considered a CMD, we did not include it for this study, as the purpose of the larger study was to deliver an intervention around depression/ anxiety/suicide risk at the primary care level. It was opined that management of alcohol use disorders is more complicated and would be a challenge within existing resources for the primary care facilities targeted, and could be introduced at a later stage.

More men had moved out of the village for seasonal work in factories and farms located in other towns, and hence were unavailable for interviews even after repeated attempts were made to contact them. This led to a higher proportion of women in the villages being screened by the interviewers. The higher occupation rate in men, and that more men than women had completed high school or graduation, is possibly a reflection of the fact that this was a study based in rural communities, where traditionally men are employed in field work or in other unorganised sectors in large numbers as labourers, while women are often unemployed or are housewives. Data from the district (http://www.westgodavari.ap. gov.in/Cencus.apo) suggest that males have higher literacy rates. Males are more likely to continue their education than women, especially in rural settings, which may be the reason for more men having completed high school or graduation. The skewed school dropout rates have led to the government developing specific programmes to increase schooling among girls in India (http:// mhrd.gov.in/incentives).

The prevalence of adults at risk of CMD in this study was less than that reported by the NMHS. ${ }^{6}$ One reason could be that we did not include alcohol and substance use disorders, which showed a $5 \%$ prevalence in the NMHS. Moreover, this study was based in a rural population, which is expected to have lower prevalence rates compared to urban populations, ${ }^{7,8,26}$ which may have led to the lower estimates. Another reason could be the differences in tools used in this study compared with those used in the NMHS. In the NMHS, an adapted version of the MINI International Neuropsychiatric Interview was used, whereas PHQ9 and GAD7 were used in this study. Recent research has reported that, compared with MINI, PHQ9 has a sensitivity of $86 \%$ and specificity of $78 \%{ }^{27}$ Given the differences in methods used in this study vis-à-vis the NMHS, we feel that our results are similar to those obtained in the NMHS and provide independent validation of the NMHS findings. The differences in observed prevalence could be due to a number of factors, as listed above. The NMHS, although a significant survey, had some methodological limitations, particularly the use of an adapted MINI with no information currently available about the validity of the adapted tools, and selection of some states based on 'availability of interested partners' ${ }^{6}$ which may be potential sources of bias. The value of data collected from large studies using appropriate study designs, such as the SMART Mental Health Project, will add to existing research from India (including the NMHS) and should lead to more accurate pooled estimates of mental disorders across India in future.

The adjusted model showed that female gender, being at least 30 years old, being uneducated and being separated/divorced/widowed were associated with higher risk of CMD. Depression, anxiety and suicide risk were significantly higher among females. This is similar to findings from other studies conducted nationally and internationally. ${ }^{6,26,28}$ The association between lower education and depression has also been reported earlier. ${ }^{26}$ In this study, the risk for CMD increased with increasing age. Earlier research from

\begin{tabular}{|c|c|c|c|c|}
\hline Severity & Score & Total population (\%) & Total males (\%) & Total females (\%) \\
\hline \multicolumn{5}{|l|}{ Anxiety score } \\
\hline No anxiety & $0-4$ & 19965 (89.2) & 9291 (91.1) & $10674(87.6)$ \\
\hline Mild & $5-9$ & $2099(9.4)$ & $798(7.8)$ & 1301 (10.7) \\
\hline Moderate & $10-14$ & $228(1.0)$ & $75(0.7)$ & $153(1.3)$ \\
\hline Severe & $\geq 15$ & $85(0.4)$ & $30(0.3)$ & $55(0.5)$ \\
\hline \multicolumn{5}{|l|}{ Depression score } \\
\hline No depression & $0-4$ & $19150(85.6)$ & $8956(87.9)$ & $10194(83.7)$ \\
\hline Mild & $5-9$ & 2681 (12.0) & 1049 (10.3) & 1632 (13.4) \\
\hline Moderate & $10-14$ & $372(1.7)$ & $131(1.3)$ & $241(2.0)$ \\
\hline Severe & $\geq 15$ & $174(0.8)$ & 58 (0.6\%) & $116(1.0)$ \\
\hline
\end{tabular}


Table 4 Univariate and multivariate models of the effect of sociodemographic variables on screen-positive status $^{\mathrm{a}}(\mathrm{N}=22377)$

\begin{tabular}{|c|c|c|c|c|c|c|}
\hline Variable & & $N(\%)$ & Unadjusted odds ratio $(95 \% \mathrm{Cl})$ & $P$-value & Adjusted odds ratio $(95 \% \mathrm{Cl})$ & $P$-value \\
\hline \multirow[t]{2}{*}{ Gender } & Male & $408(1.82)$ & 1.0 & & 1.0 & \\
\hline & Female & $763(3.41)$ & $1.60(1.42-1.81)$ & $<0.0001$ & $1.40(1.20-1.64)$ & $<0.0001$ \\
\hline \multirow[t]{3}{*}{ Age category } & 18 to 29 & $159(0.71)$ & 1.0 & & 1.0 & \\
\hline & 30 to 59 & $588(2.63)$ & $1.80(1.51-2.15)$ & $<0.0001$ & $1.57(1.28-1.92)$ & $<0.0001$ \\
\hline & $60+$ & $424(1.89)$ & $3.91(3.25-4.72)$ & $<0.0001$ & $2.81(2.23-3.53)$ & $<0.0001$ \\
\hline \multirow[t]{2}{*}{ Occupation category } & Housewife/retired/others & $601(2.69)$ & 1.0 & & 1.0 & \\
\hline & Unorganised/Organised sector & $570(2.55)$ & $0.67(0.60-0.76)$ & $<0.0001$ & $0.88(0.76-1.02)$ & 0.10 \\
\hline \multirow[t]{2}{*}{ Education category } & Any education & $624(2.79)$ & 1.0 & & 1.0 & \\
\hline & No education & $547(2.44)$ & $1.87(1.66-2.10)$ & $<0.0001$ & $1.36(1.19-1.85)$ & $<0.0001$ \\
\hline \multirow[t]{3}{*}{ Marital status } & Never married & $49(0.22)$ & 1.0 & & 1.0 & \\
\hline & Currently married & $864(3.86)$ & $2.16(1.89-2.89)$ & $<0.0001$ & $1.17(0.84-1.62)$ & 0.36 \\
\hline & Separated/divorced/ widowed & $258(1.15)$ & $5.26(3.85-7.19)$ & $<0.0001$ & $1.68(1.16-2.44)$ & 0.01 \\
\hline
\end{tabular}

India also indicated that depression is higher in older individuals compared with younger ones, but drops slightly in those more than 60 years old. ${ }^{6}$ The highest risk for CMD among those older than 60 years could reflect the most common stressors identified in the community - financial loss, death or illness of loved ones, and lack of any jobs. Older individuals may be less financially independent, leading to an increased effect of any financial crisis on them, compared with younger individuals, who may be more financially stable and have a job. This was seen in the unadjusted model, where being employed was significantly associated with reduced risk of CMD, but was not significant in the multivariate model. With age, it is also more likely that one would experience a higher proportion of illness and death among family members and friends, especially if they are also older individuals. However, more research including qualitative interviews needs to be conducted to understand the reasons more clearly. Prior research from both national ${ }^{26}$ and international ${ }^{20}$ populations have shown that both number and type of stressors are related to mental disorders, and the common stressors associated with depression and anxiety in this study are similar to those identified previously in India. ${ }^{26}$

CMD should be manageable at the primary care level by nonspecialist health workers and primary care doctors and nurses as per the World Health Organization guidelines. ${ }^{29}$ However, even such basic training is not currently provided to primary care health workers and doctors. While the National Mental Health Policy $^{30}$ and World Health Organization's Mental Health Action Plan $^{31}$ recommend community-based services to be delivered by primary care workers, the execution of such is not uniform across the country, and, where present, it is not necessarily delivered or evaluated on a regular basis. Use of mental health services, though part of the larger project objective, was not a focus for this paper, and data related to use of mental health services are under analysis. However, data collected using similar tools and methods from a predominantly tribal population group from the same district showed a baseline mental health service use of $0.8 \%$, which increased to $12.6 \%$ following intervention. ${ }^{32,33}$ The study highlighted the low uptake of mental health services in the community, low awareness about CMD, lack of mental health services, and the effect of providing basic mental health services in increasing mental health services uptake. It is thus important not only to augment current primary care health workers' training to include training in mental health, but also to provide them with skills and technical guidance that is evidence based and uses their time efficiently to provide mental healthcare. One way to do so is by leveraging mobile technology, which is increasingly present across rural communities in India,

\begin{tabular}{|c|c|c|c|}
\hline Question related to stress & $\begin{array}{l}\text { Number of events in those with } \\
\text { scores } \geq 10 \text { for anxiety/depression- } \\
n^{\mathrm{a}} / \mathrm{N}^{\mathrm{b}}(\%)\end{array}$ & $\begin{array}{l}\text { Number of events in those with scores } \\
<10 \text { for anxiety/depression- } \mathrm{n} / \mathrm{N}(\%)\end{array}$ & $P$-value \\
\hline Did you get married in the past 1 year? & $7 / 573(1.2)$ & $296 / 18605(1.6)$ & 0.485 \\
\hline Did you get separated/divorced in the past 1 year? & $8 / 103(7.8)$ & 40/1699 (2.4) & 0.001 \\
\hline Did your spouse die in the past 1 year? & 18/119 (15.1) & 184/2102 (8.8) & 0.019 \\
\hline Did any of your loved ones die in the past 1 year? & $99 / 663(14.9)$ & $1472 / 21714(6.8)$ & $<0.001$ \\
\hline Did you have a baby in the past 1 year? & $14 / 637(2.2)$ & 687/19 604 (3.5) & 0.076 \\
\hline Did you lose your job in the past 1 year? & 3/409 (0.7) & 90/10 $632(0.8)$ & 0.806 \\
\hline Did you retire in the past 1 year? & 2/348 (0.6) & 17/10 $553(0.2)$ & 0.069 \\
\hline $\begin{array}{l}\text { Did you or your loved one suffer any major illness/injury in the } \\
\text { past } 1 \text { year? }\end{array}$ & $125 / 663(18.9)$ & 1910/21714 (8.8) & $<0.001$ \\
\hline $\begin{array}{l}\text { Did you have any problems with your boyfriend/girlfriend in the } \\
\text { past } 1 \text { year? }\end{array}$ & 25/644 (3.9) & 192/21 $207(0.9)$ & $<0.001$ \\
\hline $\begin{array}{l}\text { Did you have any major problems with your school/college } \\
\text { performance in the past } 1 \text { year? }\end{array}$ & $6 / 336(1.8)$ & 30/10398 (0.3) & $<0.001$ \\
\hline Did you have any major financial problems in the past 1 year? & $366 / 653(56.0)$ & $6932 / 21490(32.3)$ & $<0.001$ \\
\hline $\begin{array}{l}\text { Did you face any natural disaster or stolen livestock or death of } \\
\text { livestock, or crop failure or forced migration leading to loss of } \\
\text { income or property? }\end{array}$ & $119 / 654(18.2)$ & $2609 / 21463(12.2)$ & $<0.001$ \\
\hline $\begin{array}{l}\text { Did you experience any major crime or were a victim of a major } \\
\text { crime such as robbery, assault/beating, murder/attempted } \\
\text { murder, sexual violence? }\end{array}$ & $33 / 657(5.0)$ & $172 / 21605(0.8)$ & $<0.001$ \\
\hline
\end{tabular}


to not only deliver mental health services, but also to facilitate training and monitoring. The SMART Mental Health Project uses such a paradigm and proposes to use it in rural settings as described in this paper and evaluate the feasibility of implementing such an intervention.

Additional information available about stressors in this community should be factored in while developing mental healthcare systems which are specifically oriented to the community's needs, especially given that financial loss was identified as the most important stressor related to CMD. In recent times, farmer suicide due to financial debt has been identified as a major issue in rural India, ${ }^{34}$ and there has been a debate about whether suicide is a result of untreated mental disorders or due to financial crisis; that is, whether a failure of mental health professionals to provide care in such rural communities or failure of state policies to tackle the financial crises is to blame. ${ }^{35}$ Although this study did not provide specific details on farmers, it showed that CMD was statistically significantly associated with financial loss, and this was the most common stressor affecting both men and women in this community. Farming is the most common occupation in this community, with $90 \%$ of the land under cultivation. Our data add to the debate on the intricate link between financial loss and mental disorders. To the best of our knowledge, no initiatives have been developed in India to capture the effects of stress on the mental health of the community or to address them. Developing mental health promotion and prevention models which address such gaps could be an important step towards public mental health, at a local and possibly also a national level.

In conclusion, this study provided important information from a large rural population using standard tools, which adds to the data from the NMHS, and identified important stressors that affected these particular communities. The study showed that CMD related to stressors such as financial loss or illness and death of loved ones was prevalent but remained unidentified in the community. This calls for a closer look at national policies that focus on providing primary healthcare and integrating mental health in it, as well as the role of mental health communities in promoting mental health and identifying mechanisms in partnership with key stakeholders to alleviate the burden due to mental disorders, especially in disadvantaged rural settings.

Sudha Kallakuri, MSC, Research Assistant, George Institute for Global Health, New Delhi, India; Siddhardha Devarapalli, MA, MPS, MPhil, Research Fellow, George Delhi, India; Siddhardha Devarapalli, MA, MPS, MPhil, Research Fellow, George
Institute for Global Health, New Delhi, India; Anadya Prakash Tripathi, MSc, Lead Biostatistician, George Institute for Global Health, New Delhi, India; Anushka Patel MBBS, SM, PhD, FRACP, FCSANZ, FAHMS, Chief Scientist, George Institute for Globa Health, Sydney, Australia and Professor of Medicine, University of New South Wales, Sydney, Australia; Pallab K Maulik, MD, PhD, MSc, Deputy Director and Head of Research, George Institute for Global Health, New Delhi, India, and Associate Professor, Faculty of Medicine, University of New South Wales, Sydney, Australia and Senior Research Associate, George Institute for Global Health, University of Oxford, Oxford, UK.

Correspondence: Pallab K. Maulik, George Institute for Global Health India, 311-312 Elegance Tower, Jasola, New Delhi 110025, India. Email: pmaulik@georgeinstitute.org.in

First received 3 Apr 2018, accepted 5 May 2018

\section{Funding}

This project was supported by the Wellcome Trust/DBT India Alliance Fellowship (Grant No: IA 1/13/1/500879), awarded to P.K.M. as an Intermediate Career Fellow. The funders had no role in this paper.

\section{References}

1 Office of the Registrar General \& Census Commissioner. Rural Urban Distribution of Population, Census of India 2011. Ministry of Home Affairs, Government of India, 2011.
2 Srivastava RK, Bachani D. Burden of NCDS, Policies and programme for prevention and control of NCDs in India. Indian J Community Med 2011; 36(suppl 1): S7-12.

3 Singh S, Badaya S. Health care in rural India: a lack between need and feed. South Asian J Cancer 2014; 3(2): 143-4.

4 Reddy KS. India's aspirations for universal health coverage. N Engl J Med 2015; 373: $1-5$.

5 Thornicroft G, Chatterji S, Evans-Lacko S, Gruber M, Sampson N, AguilarGaxiola S, et al. Under treatment of people with major depressive disorder in 21 countries. Br J Psychiatry 2017; 210: 119-24.

6 Gururaj G, Varghese M, Benegal V, Rao GN, Pathak K, Singh LK, et al. National Mental Health Survey of India, 2015-16. Prevalence, Pattern and Outcomes. National Institute of Mental Health and Neuro Sciences, 2016.

7 Gururaj G, Varghese M, Benegal V, Rao GN, Pathak K, Singh LK, et al. National Mental Health Survey of India, 2015-16: Summary. National Institute of Mental Health and Neuro Sciences, 2016.

8 Maulik PK, Devarapalli S, Kallakuri S, Praveen D, Jha V, Patel A. Systematic Medical Appraisal, Referral and Treatment (SMART) mental health programme for providing innovative mental health care in rural communities in India. Global Mental Health 2015; 2: e13.

9 Maulik PK, Devarapalli S, Kallakuri S, Tewari A, Chilappagari S, Koschorke M, et al. Evaluation of an anti-stigma campaign related to common mental disorders in rural India: a mixed methods approach. Psychol Med 2017; 47: 565-75.

10 The WHO World Mental Health Survey Consortium. Prevalence, severity, and unmet need for treatment of mental disorders in the world health organization world mental health surveys. JAMA 2004; 291: 2581-90.

11 Patel V, Weiss HA, Chowdhary N, Naik S, Pednekar S, Chatterjee S, et al. Lay health worker led intervention for depressive and anxiety disorders in India: impact on clinical and disability outcomes over 12 months. Br J Psychiatry 2011; 199: 459-66.

12 Maulik PK, Tewari A, Devarapalli S, Kallakuri S, Patel A. The Systematic Medical Appraisal, Referral and Treatment (SMART) mental health project: development and testing of electronic decision support system and formative research to understand perceptions about mental health in rural India. PLOS ONE 2016; 11: e0164404.

13 Pfizer Inc. Patient Health Questionnaire-9. Pfizer, 2013 (http://www.phqscreeners.com/sites/g/files/g10016261/f/201412/PHQ-9_English.pdf, accessed 29 September 2016)

14 Pfizer Inc. Instructions for Patient Health Questionnaire (PHQ) and GAD-7 Measures. Pfizer, 2013 (https://phqscreeners.pfizer.edrupalgardens.com/sites/ g/files/g10016261/f/201412/instructions.pdf, accessed 29 September 2016).

15 Pfizer Inc. Generalized Anxiety Disorders-7. Pfizer, 2013 (http://www.phqscreeners.com/sites/g/files/g10016261/f/201412/GAD-7_English.pdf, accessed 29 September 2016)

16 Kochhar PH, Rajadhyaksha SS, Suvarna VR. Translation and validation of brief patient health questionnaire against DSM IV as a tool to diagnose major depressive disorder in Indian patients. J. Post Grad Med 2007; 53: 102-7.

17 Gilbody S, Richards D, Brealey S, Hewitt C. Screening for depression in medical settings with the Patient Health Questionnaire (PHQ): a diagnostic meta-anaIysis. J Gen Intern Med 2007; 22: 1596-602.

18 Wittkampf KA, Naeije L, Schene AH, Huyser J, van Weert HC. Diagnostic accuracy of the mood module of the Patient Health Questionnaire: a systematic review. Gen Hosp Psychiatry 2007; 29: 388-95.

19 Musiat P, Conrod P, Treasure J, Tylee A, Williams C, Schmidt U. Targeted prevention of common mental health disorders in university students: randomised controlled trial of a transdiagnostic trait-focused web-based intervention. PLOS ONE 2014; 9: e93621.

20 Maulik PK, Eaton WW, Bradshaw CP. The effect of social networks and socia support on common mental disorders following specific life events. Acta Psychiatr Scand 2010; 122: 118-28.

21 Lund C, Tomlinson M, De Silva M, Fekadu A, Shidhaye R, Jordans M, et al. PRIME: a programme to reduce the treatment gap for mental disorders in five low-and middle-income countries. PLOS Med 2012; 9: e1001359.

22 Institute of Psychiatry, King's College London. Barriers to Access to Care Evaluation - Treatment Stigma Subscale (BACE-TS Version 3). Institute of Psychiatry, 2011.

23 World Health Organization. WHO ASSIST Version 3.0. World Health Organization, 2010.

24 Editorial office. Sex and gender in psychiatry. Lancet Psychiatry 2016; 3: 999.

25 Schiebinger L, Leopold SS, Miller VM. Editorial policies for sex and gender analysis. Lancet 2016; 388: 2841-42.

26 Grover S, Dutt A, Avasthi A. An overview of Indian research in depression. Indian J Psychiatry 2010; 52(Suppl 1): S178-88.

27 Volker D, Zijlstra-Vlasveld MC, Brouwers EP, Homans WA, Emons WH, van der Feltz-Cornelis $\mathrm{CM}$. Validation of the patient health auestionnaire-9 for major 
depressive disorder in the occupational health setting. J Occup Rehabil 2016; 26: $237-44$

28 Kessler RC, Bromet EJ. The epidemiology of depression across cultures. Annul Rev Public Health 2013; 34: 119-38.

29 World Health Organization. WHO Mental Health Gap Action Programme (mhGAP). WHO, 2011 (http://www.who.int/mental_health/mhgap/en/, accessed 29 September 2016).

30 Ministry of Health and Family Welfare. New Pathways New Hope National Mental Health Policy of India. Government of India, 2014

31 World Health Organization. Mental Health Action Plan 2013-2020. World Health Organization, 2013.

32 Maulik PK, Kallakuri S, Devarapalli S, Vadlamani VK, Jha V, Patel A. Increasing use of mental health services in remote areas using mobile technology: a pre-post evaluation of the SMART Mental Health project in rural India. J Glob Health 2017; 7: 010408.

33 Tewari A, Kallakuri S, Devarapalli S, Jha V, Patel A, Maulik PK. Process evaluation of the systematic medical appraisal, referral and treatment (SMART) mental health project in rural India. BMC Psychiatry 2017; 17: 385

34 Merriott D. Factors associated with the farmer suicide crisis in India. J Epidemiol Glob Health 2016; 6: 217-27.

35 Rao TSS, Gowda MR, Ramachandran K, Andrade C. Prevention of farmer suicides: greater need for state role than for a mental health professional's role. Indian J Psychiatry 2017; 59: 3-5. 